ఠ

\title{
Metabolic syndrome in hemodialysis patients as a risk factor for new-onset diabetes mellitus after renal transplant: a prospective observational study
}

This article was published in the following Dove Press journal:

Diabetes, Metabolic Syndrome and Obesity:Targets and Therapy

17 September 2013

Number of times this article has been viewed

Josep Bonet ${ }^{\prime}$

Albert Martinez-Castelao²

Beatriz Bayés'

'Department of Nephrology, Hospital Universitari Germans Trias i Pujol, Badalona, Spain; ${ }^{2}$ Department of Nephrology, Hospital Universitari de Bellvitge, IDIBELL, Hospitalet de Llobregat, Barcelona, Spain
Correspondence: Dr Josep Bonet Department of Nephrology, Hospital Universitari Germans Trias i Pujol, Carretera de Canyet, S/N, 08916

Badalona, Spain

Tel +34934978 898

Fax +34 934978852

Email jbonet.germanstrias@gencat.cat
Purpose: Metabolic syndrome is a cluster of biochemical abnormalities including cardiovascular and diabetes risk factors. The development of diabetes mellitus after renal transplant represents a major posttransplant complication that may adversely affect graft/patient survival. The aim of this study was to assess the role of metabolic syndrome in patients on hemodialysis as a risk factor for the incidence of new-onset diabetes mellitus after renal transplant.

Patients and methods: This was a prospective observational epidemiologic study carried out in adult nondiabetic patients undergoing chronic hemodialysis and on the renal transplant waiting list between November 2008 and April 2009. Patients were followed up from Visit 1 (baseline) to 6 months after the renal transplant. The analysis of the role of metabolic syndrome in hemodialysis patients as a risk factor for the incidence of new-onset diabetes mellitus after renal transplant included the estimation of relative risk and its $95 \%$ confidence interval (CI).

Results: A total of 383 evaluable patients were entered into the study (mean age, 52.7 years; male, $57.7 \%$; Caucasian, 90.1\%). The prevalence of metabolic syndrome on hemodialysis was $30.4 \%$ (95\% CI, 25.8\%-35.4\%). Hypertension was the most prevalent criterion for metabolic syndrome $(65.0 \%)$, followed by low levels of high-density lipoprotein cholesterol $(52.7 \%)$, abdominal obesity (36.2\%), hypertriglyceridemia (32.4\%), and impaired glucose (8.9\%). After the renal transplant, the prevalence of metabolic syndrome was still $25.8 \%$. During the posttransplant period, the incidence of new-onset diabetes mellitus reached $13.0 \%(95 \%$ CI, 7.8\%-20.6\%) and patients with pretransplant metabolic syndrome were 2.6 times $(95 \%$ CI, 1.043-6.608) more likely to develop new-onset diabetes mellitus after the renal transplant than those without metabolic syndrome.

Conclusion: The presence of metabolic syndrome in patients undergoing hemodialysis represents an independent risk factor for the incidence of new-onset diabetes mellitus after renal transplant.

Keywords: dialysis, kidney transplantation, metabolic syndrome X, posttransplant diabetes

\section{Introduction}

Metabolic syndrome is a cluster of biochemical and clinical abnormalities such as abdominal obesity, dyslipidemia, hypertension, and/or impaired blood glucose occurring simultaneously in a single individual. ${ }^{1,2}$ Even though the definition and pathogenesis of metabolic syndrome is still under debate, it is becoming a public health problem due to its effect on cardiovascular diseases. Indeed, metabolic syndrome increases the risk of cardiovascular diseases, ${ }^{3,4}$ even if it is just as a result of the combination of the cardiovascular risk factors defining metabolic syndrome. ${ }^{5}$ In addition, metabolic syndrome is closely associated with insulin resistance, ${ }^{1}$ a metabolic disorder characterized by impaired tissue responsiveness to the normal action of insulin ${ }^{6,7}$ that has been considered as one of the 
underlying causes of diabetes mellitus. ${ }^{8,9}$ In fact, metabolic syndrome has been suggested to be a predisease state beyond cardiovascular disease and diabetes, in which the infiltration of macrophages into adipose tissue characterized by an increased number of crown-like structures and inflammation are crucial for its metabolic consequences. ${ }^{2}$

The development of new-onset diabetes after renal transplant (NODAT) represents a major posttransplant complication that may adversely affect graft/patient survival ${ }^{10-13}$ and increase the risk of cardiovascular events. ${ }^{13,14}$ Several factors have been identified as being related to the development of NODAT, some of which are potentially modifiable factors whose identification would help to develop strategies to improve outcomes. Among these potentially modifiable factors are cytomegalovirus/hepatitis $\mathrm{C}$ virus infection, ${ }^{11,15,16}$ early low-grade proteinuria, ${ }^{17}$ immunosuppressive therapy, ${ }^{10,11,16-18}$ arterial pressure/antihypertensive treatment, ${ }^{17,19}$ overweight/obesity, ${ }^{10,11,16,19,20}$ increased triglyceride levels, ${ }^{10,14,21}$ and higher blood glucose levels. ${ }^{14,18,22}$ Even though some of these factors also define metabolic syndrome, the specific role of metabolic syndrome in the development of diabetes has not been completely clarified yet. However, three recently published studies have shed some light on this matter, showing that diagnosis of metabolic syndrome after renal transplant ${ }^{23,24}$ and within the month prior to transplant ${ }^{25}$ was associated with an increased risk of NODAT.

In light of all the above, the aim of this study was to expand the information available about the relationship between metabolic syndrome and diabetes by assessing the role of metabolic syndrome in patients on hemodialysis as a risk factor for the incidence of NODAT.

\section{Material and methods}

This study was conducted in accordance with the Guidelines for Ethical Review of Epidemiological Studies, the
Declaration of Istanbul 2008, the World Medical Association 2000 Declaration of Helsinki, all its amendments, and national regulations. The study was approved by the ethics committee of Hospital Germans Trias i Pujol (Badalona, Spain) and all patients gave their written informed consent prior to their inclusion in the study.

\section{Patient population}

This study included all patients meeting selection criteria that accepted to participate between November 2008 and April 2009. The main inclusion criteria comprised patients aged 18 years or older, undergoing chronic hemodialysis, without diabetes mellitus, and on the renal transplant waiting list. The main exclusion criteria were patients with any clinically relevant medical condition that, in the opinion of the investigator, made study participation unadvisable or those with a cognitive impairment precluding patients from giving their informed consent.

\section{Study design}

This was a prospective observational epidemiologic study conducted at 22 Catalonian dialysis centers (Spain).

The study follow-up comprised two different periods: pretransplant and posttransplant periods (Figure 1). The pretransplant period ranged from study Visit 1 (baseline) to renal transplant. The length of this period was variable, as it was not possible to foresee the time until renal transplant. Therefore, a maximum length of 30 months from baseline was established, based on the consideration that this time was sufficient (from the perspective of the authors' previous experience in renal transplants carried out in Catalonia) to enable practically all patients to receive the renal transplant. During this period, a second and third visit at 12 months and 24 months were performed in those patients who had not received the renal transplant by these months. Thus, the

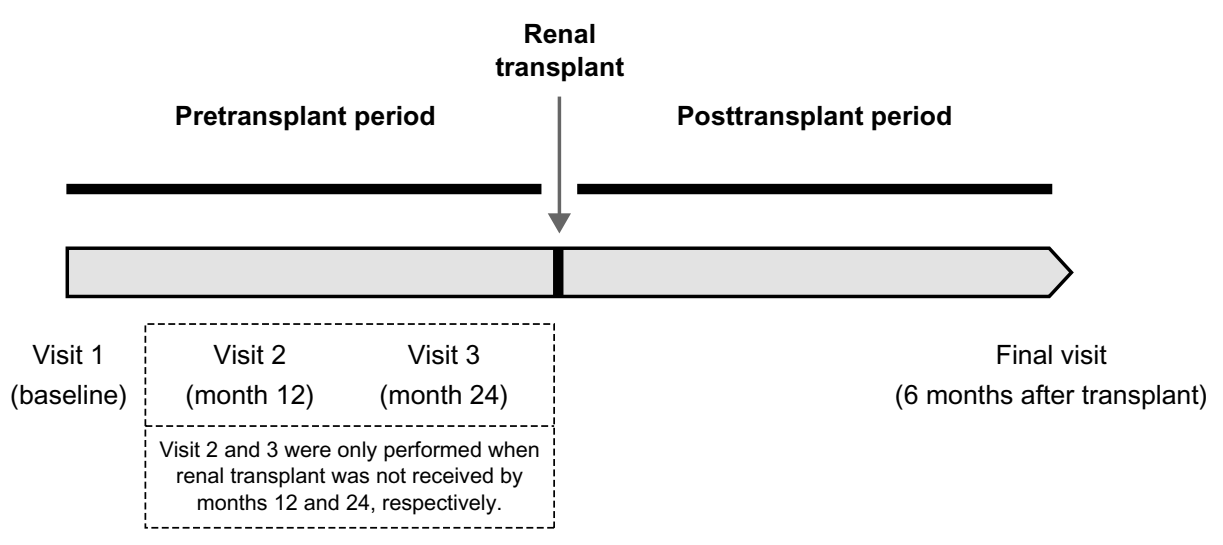

Figure I Overall study design. 
number of study visits in the pretransplant period could range from one to three depending on the elapsed time between baseline and renal transplant. However, in the posttransplant period, only one study visit was performed 6 months after the renal transplant (final visit). Therefore, the maximum length of the study follow-up was 36 months.

All treatments were administered according to routine clinical practice and no restrictions regarding patients' treatment were specified in the study protocol.

\section{Assessments}

Data were collected by review of medical charts, physical examination, and information provided by patients during the study visits, according to routine clinical practice. Data collected at Visit 1 (baseline) included: demographics (age, gender, and ethnicity), anthropometrics (weight and height), family history of diabetes mellitus, renal function assessment and replacement treatment (hemodialysis start date), serology (hepatitis $\mathrm{C}$ virus, hepatitis $\mathrm{B}$ virus, and human immunodeficiency virus), concomitant treatments (antihypertensive drugs, lipid-lowering therapies, erythropoiesis-stimulating agents, phosphate binders, vitamin D, calcimimetics, and anticoagulant therapies), metabolic syndrome assessment based on the National Cholesterol Education Program Adult Treatment Panel III (ATP III) definition (waist circumference, blood pressure, high-density lipoprotein [HDL] cholesterol, triglycerides, and fasting blood glucose), concomitant cardiovascular diseases/cerebrovascular events, and cardiovascular risk factors (lack of regular exercise, snoring, smoking habit, and alcohol consumption).

When Visit 2 (12 months) and Visit 3 (24 months) were performed, the data collected included serology, concomitant treatments, metabolic syndrome assessment according to ATP III criteria, concomitant cardiovascular diseases/cerebrovascular events, and cardiovascular risk factors.

Six months after renal transplant, data on renal transplant (date of transplant, donor, immunosuppressive therapy, and graft rejection), metabolic syndrome assessment according to ATP III criteria, and NODAT were also collected. The diagnosis of metabolic syndrome was made - according to ATP III criteria - when three or more of the following risk determinants were present: abdominal obesity (waist circumference $>102 \mathrm{~cm}$ in men or $>88 \mathrm{~cm}$ in women), hypertriglyceridemia (triglycerides $\geq 150 \mathrm{mg} / \mathrm{dL}$ ), low levels of HDL cholesterol ( $<40 \mathrm{mg} / \mathrm{dL}$ in men or $<50 \mathrm{mg} / \mathrm{dL}$ in women), hypertension (blood pressure $\geq 130 \mathrm{mmHg} / \geq 85 \mathrm{mmHg}$ ), and impaired glucose (fasting blood glucose $\geq 110 \mathrm{mg} / \mathrm{dL}$ ). ${ }^{1}$ Diabetes mellitus was diagnosed based on the American
Diabetes Association criteria, either when symptoms of diabetes plus casual blood glucose concentration $\geq 200 \mathrm{mg} / \mathrm{dL}$ were present or when fasting blood glucose was $\geq 126 \mathrm{mg} / \mathrm{dL}$ or when the 2-hour postload glucose was $\geq 200 \mathrm{mg} / \mathrm{dL}$ during the oral glucose tolerance test. ${ }^{26}$

\section{Statistical considerations}

The primary efficacy endpoint was the presence of metabolic syndrome in patients on hemodialysis as a risk factor for the incidence of NODAT. Analysis of this primary endpoint included the estimation of relative risk and its $95 \%$ confidence interval (CI).

The secondary endpoints were the most prevalent criteria for metabolic syndrome in patients undergoing hemodialysis on the waiting list for renal transplant, the prevalence of metabolic syndrome without diabetes mellitus in this patient population, the concomitant cardiovascular diseases/cerebrovascular events and cardiovascular risk factors before renal transplant, and the incidence of NODAT. Analysis of these secondary endpoints was performed using descriptive methods (frequencies and valid percentages for categorical variables, and measures of central tendency and dispersion for quantitative variables). In addition, 95\% CI for the prevalence of metabolic syndrome without diabetes mellitus in patients undergoing hemodialysis on the waiting list for renal transplant and for incidence of NODAT were also calculated.

Missing data were not considered in the analyses, which were performed with SPSS Statistics version 17.0 (SPSS Inc, Chicago, IL, USA).

\section{Results \\ Patient characteristics}

A total of 418 patients were screened from a total Catalonian population of 7.5 million inhabitants (990 new patients in substitutive renal therapy and 471 renal transplants in 2008; and 1,064 new patients in substitutive renal therapy and 524 renal transplants in 2009), representing, at that time, $49.5 \%$ of all nondiabetic patients on the renal transplant waiting list in Catalonia (Spain). Two of the screened patients were screening failures and 33 were nonevaluable as a result of insufficient data available for the study. Thus, the evaluable population comprised a total of 383 patients (Figure 2). Baseline characteristics of evaluable patients are described in Table 1.

\section{Pretransplant period}

Patients remained on hemodialysis an average (standard deviation [SD]) of 4.8 (4.5) years before receiving a renal transplant. 


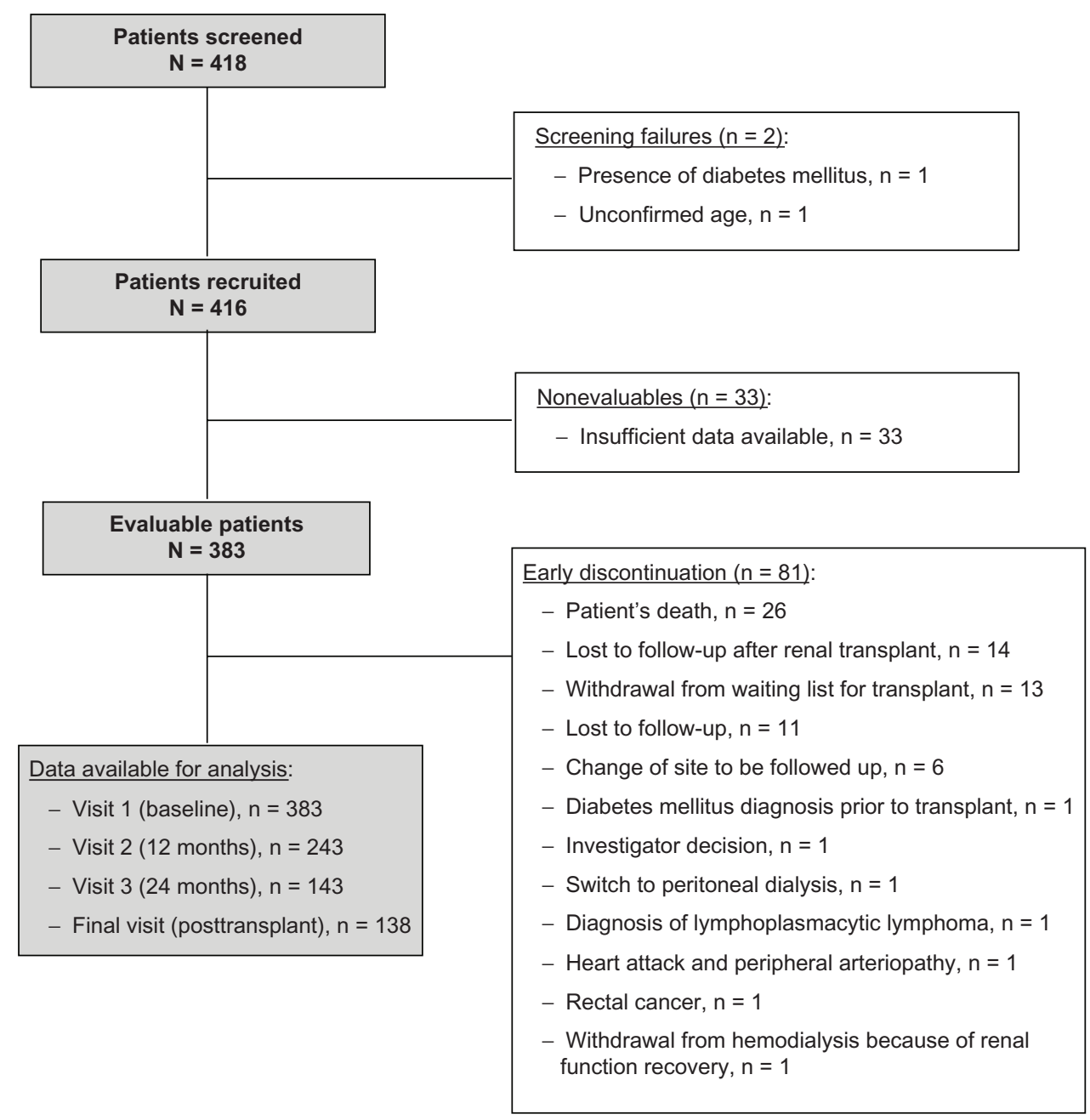

Figure 2 Summary of patient disposition.

Serology tests conducted before renal transplant showed that 41 (10.8\%) patients tested positive for hepatitis $\mathrm{C}$ virus, three $(0.8 \%)$ patients tested positive for hepatitis B virus, and two $(0.5 \%)$ patients for human immunodeficiency virus.

In the last pretransplant visit, 206 (55.5\%) patients were receiving antihypertensive treatment (calcium channel blockers, $\mathrm{n}=103$; beta-blockers, $\mathrm{n}=89$; alpha-blockers, $\mathrm{n}=53$; angiotensin II receptor antagonists, $\mathrm{n}=52$; angiotensin-converting enzyme inhibitors, $n=51$; loop of Henle diuretics, $n=21$; others, $n=23)$, and $164(44.1 \%)$ patients were receiving lipid-lowering treatment (statins, $\mathrm{n}=141$; fibrates, $\mathrm{n}=19$; ezetimibe, $\mathrm{n}=4$; others, $\mathrm{n}=8$ ). Other concomitant treatments included erythropoiesisstimulating agents (307 [82.5\%] patients), phosphate binders (337 [90.8\%] patients), vitamin D (197 [53.2\%] patients), calcimimetics (170 [44.4\%] patients), and anticoagulant therapy (91 [24.5\%] patients).
The assessment of metabolic syndrome criteria showed that hypertension was the most prevalent criterion (234 [65.0\%] patients), followed by low levels of HDL cholesterol (187 [52.7\%] patients), abdominal obesity (118 [36.2\%] patients), hypertriglyceridemia (118 [32.4\%] patients), and impaired glucose (32 [8.9\%] patients). In addition, the prevalence of metabolic syndrome without diabetes mellitus in this patient population was $30.4 \%$ (95\% CI, 25.8\%-35.4\%). The characteristics of patients with pretransplant metabolic syndrome are described in Table 2.

During this period, 107 (28.8\%) patients reported having had at least one cardiovascular disease (peripheral arteriopathy, $n=49$; carotid artery atherosclerosis, $n=34$; angina pectoris, $\mathrm{n}=33$; heart attack, $\mathrm{n}=16$; congestive heart failure, $n=14$; coronary revascularization, $\mathrm{n}=10$; deep venous thromboembolism, $\mathrm{n}=7$; pulmonary thromboembolism, $\mathrm{n}=3$ ). Additionally, $28(7.3 \%)$ patients 
Table I Baseline patient characteristics $(\mathrm{N}=383)$

\begin{tabular}{|c|c|}
\hline Patient characteristics & Value \\
\hline Mean age, years (SD) & $52.7(12.3)$ \\
\hline Male, n (\%) & $221(57.7)$ \\
\hline \multicolumn{2}{|l|}{ Ethnicity, n (\%) } \\
\hline Caucasian & $345(90.1)$ \\
\hline Other & $38(9.9)$ \\
\hline Mean weight, kg (SD) & $67.6(13.1)$ \\
\hline Mean height, cm (SD) & $164.3(9.5)$ \\
\hline \multicolumn{2}{|l|}{ Body mass index } \\
\hline Mean body mass index, $\mathrm{kg} / \mathrm{m}^{2}(\mathrm{SD})$ & $25.0(4.4)$ \\
\hline Body mass index $\geq 30 \mathrm{~kg} / \mathrm{m}^{2}, \mathrm{n}(\%)$ & $44(11.8)$ \\
\hline Family history of diabetes mellitus, $n(\%)$ & $81(22.3)$ \\
\hline \multicolumn{2}{|l|}{ Main CKD etiology, n (\%) } \\
\hline Glomerulonephritis & $100(26.2)$ \\
\hline Unknown & $98(25.7)$ \\
\hline Polycystic disease & $57(15.0)$ \\
\hline Vascular disease & $35(9.2)$ \\
\hline Mean waist circumference, cm (SD) & $92.9(13.2)$ \\
\hline Mean systolic blood pressure, $\mathrm{mmHg}(\mathrm{SD})$ & $134.9(20.9)$ \\
\hline Mean diastolic blood pressure, $\mathrm{mmHg}(\mathrm{SD})$ & $77.3(12.7)$ \\
\hline Mean HDL cholesterol levels, mg/dL (SD) & $45.1(13.8)$ \\
\hline Triglyceride levels, mg/dL (SD) & $144.6(82.2)$ \\
\hline Fasting blood glucose levels, mg/dL (SD) & $85.3(14.3)$ \\
\hline
\end{tabular}

Abbreviations: CKD, chronic kidney disease; HDL, high-density lipoprotein; SD, standard deviation.

reported having experienced some cerebrovascular event (ischemic stroke, $\mathrm{n}=11$; hemorrhagic stroke, $\mathrm{n}=10$; transient ischemic attack, $n=9$ ). In the last pretransplant visit, the main cardiovascular risk factor was the lack of regular exercise (213 [58.7\%] patients), followed by snoring (121 [34.0\%] patients), smoking habit (64 [17.4\%] patients), and alcohol consumption (8 [2.2\%] patients).

\section{Renal transplant}

A renal transplant was finally performed in 138 (36.0\%) patients after an average (SD) of 11.9 (8.9) months from baseline. In 119 (86.9\%) patients, renal transplants were received from a deceased donor and $17(12.6 \%)$ were relative donors. The immunosuppressive treatment was mainly based on a triple therapy composed of calcineurin inhibitors or mammalian target of rapamycin inhibitors, mycophenolate mofetil/mycophenolic acid, and prednisone (93 [76.9\%] patients). Calcineurin inhibitors were administered in 100 (84.0\%) patients (tacrolimus, $\mathrm{n}=98$; cyclosporine, $\mathrm{n}=2$ ), mammalian target of rapamycin inhibitors in 18 (15.1\%) patients (everolimus, $\mathrm{n}=11$; sirolimus, $\mathrm{n}=7$ ), mycophenolate mofetil in 42 (35.3\%) patients, mycophenolic acid in 64 (53.8\%) patients, and prednisone in $113(92.6 \%)$ patients. The latter patients received $250 \mathrm{mg}$ of prednisone at renal transplant, $125 \mathrm{mg}$ on the first day after transplant, and $20 \mathrm{mg}$ from
Table 2 Characteristics of patients with metabolic syndrome before and after renal transplant

\begin{tabular}{|c|c|c|}
\hline Characteristics & $\begin{array}{l}\text { Pretransplant } \\
\text { metabolic } \\
\text { syndrome } \\
(\mathrm{N}=|| 2)\end{array}$ & $\begin{array}{l}\text { Posttransplant } \\
\text { metabolic } \\
\text { syndrome } \\
(\mathbf{N}=\mathbf{2 4})\end{array}$ \\
\hline $\begin{array}{l}\text { Mean waist circumference, } \\
\mathrm{cm}(\mathrm{SD})\end{array}$ & $100.4(13.1)$ & $97.0(12.6)$ \\
\hline $\begin{array}{l}\text { Mean systolic blood } \\
\text { pressure, } \mathrm{mmHg}(\mathrm{SD})\end{array}$ & $141.8(19.7)$ & I38.I (I7.0) \\
\hline $\begin{array}{l}\text { Mean diastolic blood } \\
\text { pressure, } \mathrm{mmHg}(\mathrm{SD})\end{array}$ & $78.9(12.9)$ & $76.7(10.2)$ \\
\hline $\begin{array}{l}\text { Mean HDL cholesterol } \\
\text { levels, } \mathrm{mg} / \mathrm{dL}(\mathrm{SD})\end{array}$ & $37.2(7.6)$ & $45.2(11.3)$ \\
\hline $\begin{array}{l}\text { Mean triglyceride } \\
\text { levels, } \mathrm{mg} / \mathrm{dL} \text { (SD) }\end{array}$ & $189.9(89.1)$ & $225.5(100.8)$ \\
\hline $\begin{array}{l}\text { Fasting blood glucose } \\
\text { levels, mg/dL (SD) }\end{array}$ & $94.5(24.8)$ & II $0.5(26.8)$ \\
\hline Diabetes mellitus, $\mathrm{n}(\%)$ & $0(0.0)$ & $7(29.2)$ \\
\hline
\end{tabular}

Abbreviations: HDL, high-density lipoprotein; SD, standard deviation.

the second to the 15 th day after transplant. From the 16th day after transplant, patients received $15 \mathrm{mg}$ of prednisone and, after 2 months, prednisone was decreased to a maintenance dose of $5 \mathrm{mg}$ /day. Graft rejection was reported in six (4.7\%) patients (acute rejection, $\mathrm{n}=5$; chronic rejection, $\mathrm{n}=1$ ), three of whom received methylprednisolone bolus of $500 \mathrm{mg} /$ day for 3 days as transplant rejection treatment.

\section{Posttransplant period}

After the renal transplant, patients had a mean (SD) waist circumference of $93.8(12.4) \mathrm{cm}$, mean (SD) systolic blood pressure of 135.1 (19.1) mmHg, mean (SD) diastolic blood pressure of 75.8 (10.8) $\mathrm{mmHg}$, mean (SD) HDL cholesterol levels of $53.1(16.3) \mathrm{mg} / \mathrm{dL}$, mean (SD) triglyceride levels of $151.0(83.8) \mathrm{mg} / \mathrm{dL}$, and mean (SD) fasting blood glucose of $96.4(18.4) \mathrm{mg} / \mathrm{dL}$. Additionally, a total of 24 (25.8\%) patients met the criteria for metabolic syndrome. The characteristics of patients with metabolic syndrome after renal transplant are described in Table 2. The prevalence of metabolic syndrome during the follow-up did not significantly increase in patients not receiving a renal transplant in comparison to patients receiving the transplant $(P=0.124)$. In addition, the duration of hemodialysis did not significantly affect the occurrence of metabolic syndrome after the renal transplant $(P=0.425)$.

The incidence of NODAT was $13.0 \%$ (95\% CI, 7.8\%-20.6\%). Among patients receiving a renal transplant, the relative risk of developing NODAT in hemodialysis patients with metabolic syndrome was estimated to be 2.625 (95\% CI, 1.043-6.608). Therefore, patients with metabolic 
syndrome undergoing hemodialysis were 2.6 times more likely to develop NODAT than those without metabolic syndrome.

\section{Discussion}

This study showed that NODAT may affect $13.0 \%$ of patients receiving a renal transplant, among whom the presence of metabolic syndrome during hemodialysis represents a risk factor that increases the likelihood of developing NODAT by 2.6 times. Recently published studies carried out in renal transplant recipients reported NODAT as a common condition, with incidences ranging from $13.0 \%-46.3 \%$ over 5 years posttransplant. ${ }^{23-25}$ These studies also supported the association between the presence of metabolic syndrome either after renal transplant ${ }^{23,24}$ or within the month prior to transplant ${ }^{25}$ and the development of NODAT, with increased risks of 3.5 and 1.3 , respectively. ${ }^{23,25}$

This association reinforces the need for early detection of metabolic syndrome prior to transplantation in order to establish therapeutic interventions to correct metabolic syndrome defining risk factors. In the current study, the main criterion for metabolic syndrome in patients on hemodialysis was hypertension, followed by low levels of HDL cholesterol, abdominal obesity, hypertriglyceridemia, and impaired glucose, and almost one-third of patients met the criteria for metabolic syndrome. Even though the information reported by previous studies carried out in patients on hemodialysis is limited and no data is available in the specific population of nondiabetic patients, the prevalence of metabolic syndrome during hemodialysis has been shown to range from $28.7 \%-61.0 \%{ }^{27-31}$ However, the differences in the criteria used to diagnose metabolic syndrome makes their comparison difficult.

Hypertension has been described as one of the most important factors for the development of metabolic syndrome, ${ }^{27,29-31}$ together with central obesity. ${ }^{27,30,31}$ However, the criteria for central obesity also differed among the various studies, some of which measured it according to waist circumference while others used the body mass index. In the current study, even though central obesity measured as waist circumference was the third most frequent metabolic syndrome defining risk factor in patients on hemodialysis, obesity measurement according to the body mass index only accounted for $11.8 \%$ of patients. The magnitude of influence of other metabolic syndrome defining risk factors in patients on hemodialysis has not yet been fully clarified, as variable information has been reported by the different studies carried out $^{28,29,31}$ depending on the criteria used for the diagnosis of metabolic syndrome. ${ }^{30}$
After renal transplant, the current study also showed the presence of metabolic syndrome in $25.8 \%$, which did not significantly differ from patients not receiving a renal transplant. Renal transplant recipients with metabolic syndrome and/or NODAT have been shown to display a worse metabolic and cardiovascular profile despite the higher prevalence in the use of statins and antihypertensive medications. ${ }^{24}$ In the current patient population, one-half of patients were receiving antihypertensive treatment and approximately one-third were under treatment with statins in the last pretransplant visit. These results differ from those previously reported within the month prior to transplant, showing percentages of $83 \%$ and $17 \%$ for antihypertensive and statin treatments, respectively. ${ }^{25}$ The difference in results may represent the variability of patient populations, mainly in terms of blood pressure and lipid control, and health system differences in the care of renal transplant recipients. Since they constitute important risk factors for cardiovascular events, and metabolic syndrome has been shown to be a risk enhancer for cardiovascular diseases, ${ }^{3}$ increased emphasis on controlling metabolic syndrome defining factors has been recommended. ${ }^{1}$ In the current study, more than one-quarter of patients reported having had at least one cardiovascular disease and approximately 7\% having experienced some cerebrovascular event during the hemodialysis period, but no information was collected during the posttransplant period. Therefore, the lack of information on cardiovascular events after the renal transplant and the short follow-up during the study period precluded the establishing of conclusions.

The authors recognize that other limitations apart from the previously mentioned absence of collection of information on posttransplant cardiovascular events must be considered when interpreting these results. That is the case for the decreased number of patients with data available for the 6-month analyses after the renal transplant. Thus, although the study was designed as prospective to obtain stronger evidence, this reduced data available after transplant might have affected it. The authors also recognize that it would have been better to measure insulin resistance by homeostatic model of assessment - insulin resistance but, unfortunately, homeostatic model of assessment values were only available in a small percentage of patients. In addition, even though this study aimed to include all patients meeting selection criteria during the recruitment period, potential selection biases cannot be ruled out. However, the multicenter nature of the study and the predominant selection of objective secondary endpoints aimed at minimizing potential biases. In fact, the authors consider that the results obtained in the 
study are representative of renal recipients from their geographical area. However, it cannot be assured that they were representative of renal recipients from other geographical areas with different ethnic composition.

\section{Conclusion}

In conclusion, this study shows that patients with metabolic syndrome on hemodialysis were 2.6 times more likely to develop NODAT than those without metabolic syndrome. In this patient population on hemodialysis, the main metabolic syndrome risk factor was hypertension, followed by low levels of HDL cholesterol, abdominal obesity, hypertriglyceridemia, and impaired glucose. The impact of metabolic syndrome on cardiovascular events and diabetes onset reinforces the need to control metabolic syndrome risk factors. Further clinical trials confirming the role of metabolic syndrome as a predictor of NODAT and assessing the benefit of interventions targeting metabolic syndrome risk factors still need to be conducted.

\section{Acknowledgments}

This work was sponsored by Fundació Catalana de Nefrología and funded by Boehringer Ingelheim. This work was done on behalf of the SIMEDIT Study Group. All investigators of the SIMEDIT Study Group participating in the study data collection are: Josep Bonet (Hospital Universitari Germans Trias i Pujol, Badalona, Spain), Albert Martinez-Castelao (Hospital Universitari de Bellvitge, IDIBELL, Hospitalet de Llobregat, Spain), Beatriz Bayés (Hospital Universitari Germans Trias i Pujol, Badalona, Spain), Miguel Hueso-Val (Institut Nefrologic Hospitalet, Hospitalet de Llobregat, Spain), Joan Manuel Díaz-Gómez (Fundació Puigvert, Barcelona, Spain), Josep María Bronsoms-Artero (Clínica Girona, Girona, Spain), María Isabel Troya-Saborido (Hospital Germans Trias i Pujol, Badalona, Spain), Jordi Soler-García (Kidney Centers Holding SL, Reus, Spain), María del Pilar Fernández-Crespo (Institut Mèdic Badalona SL, Badalona, Spain), Francisco Maduell-Canals (Hospital Clínic Barcelona, Barcelona, Spain), Nuria Garra-Moncau (Althaia, Manresa, Spain), Montserrat Belart-Rodríguez (Sistemes Renals SA, Lleida, Spain), Mercè Homs-del-Valle (Consorci Hospitalari de Vic, Vic, Spain), Antoni Pelegrí-Santos (Centro de Dialisis Verge de Montserrat, Barcelona, Spain), Vicent Esteve-Simó (Hospital Terrassa, Terrasa, Spain), Gloria Martín-Martínez (Instituto de Hemodiálisis Barcelona, Barcelona, Spain), Silvia Collado-Nieto (Hospital del Mar, Barcelona, Spain), Rosa Ramos-Sánchez (Hospital Comarcal de Sant Antoni Abat, Vilanova i la Geltrú, Spain), Joan Fort-Ros (Hospital de la Vall
d'Hebron, Barcelona, Spain), Felipe Sarró-Sobrín (Hospital Arnau de Vilanova, Lleida, Spain), Silvia Peña-Cadierno (Hospital d'Igualada, Igualada, Spain), Carmen PuigMarí (Hospital d'Igualada, Igualada, Spain), Josep RibaPola (Hospital d'Igualada, Igualada, Spain), Mercedes Arruche-Herrero (Pius Hospital de Valls, Valls, Spain), Isabel Naval-Marcos (Althaia, Manresa, Spain), Concepción Bujons-Noguera (Hospital d'Igualada, Igualada, Spain), Montserrat Vallvé-Álvarez (Hospital Joan XXIII, Tarragona, Spain), Martí Vallés-Prats (Hospital de Girona Josep Trueta, Girona, Spain), and Francesc Barbosa-Puig (Hospital del Mar, Barcelona, Spain). Medical writing support was provided by Esther Álvarez-García and Antonio Torres-Ruiz at Dynamic SL during the preparation of this paper, funded by Fundació Catalana de Nefrología.

\section{Disclosure}

The authors of this manuscript declare that Josep Bonet has participated in clinical trials and has given speeches sponsored by Boehringer Ingelheim. Albert Martinez-Castelao has received honoraria for conferences sponsored by Abbott, Amgem, Boehringer Ingelheim, Novartis, Roche, and Shire; and has acted as consultant and board member for Abbot, Amgen, Boehringer Ingelheim, and Roche. Beatriz Bayés has no conflicts of interest in relation to this manuscript, though she has been sponsored by Novartis, Roche, Stellas, and Boehringer Ingelheim. Responsibility for opinions, conclusions, and interpretation of data lies with the authors.

\section{References}

1. National Cholesterol Education Program Expert Panel on Detection Evaluation and Treatment of High Blood Cholesterol in Adults. Third Report of the National Cholesterol Education Program (NCEP) Expert Panel on Detection, Evaluation, and Treatment of High Blood Cholesterol in Adults (Adult Treatment Panel III) final report. Circulation. 2002;106(25):3143-3421.

2. Oda E. Metabolic syndrome: its history, mechanisms, and limitations. Acta Diabetol. 2012;49(2):89-95.

3. Gami AS, Witt BJ, Howard DE, et al. Metabolic syndrome and risk of incident cardiovascular events and death: a systematic review and meta-analysis of longitudinal studies. J Am Coll Cardiol. 2007;49(4): 403-414.

4. Salminen M, Kuoppamaki M, Vahlberg T, Raiha I, Irjala K, Kivela SL. Metabolic syndrome and vascular risk: a 9-year follow-up among the aged in Finland. Acta Diabetol. 2011;48(2):157-165.

5. de la Sierra A, Romero R, Bonet J, et al. Prevalencia y características del síndrome metabólico en la población hipertensa española. [Prevalence and general features of the metabolic syndrome in the Spanish hypertensive population]. Med Clin (Barc). 2006;126(11):406-409. Spanish.

6. Haffner SM. Epidemiology of insulin resistance and its relation to coronary artery disease. Am J Cardiol. 1999;84(1A):11J-14J.

7. Kolaczynski JW, Caro JF. Insulin resistance: site of the primary defect or how the current and the emerging therapies work. J Basic Clin Physiol Pharmacol. 1998;9(2-4):281-294.

8. Groop LC. Insulin resistance: the fundamental trigger of type 2 diabetes. Diabetes Obes Metab. 1999;1(Suppl 1):S1-S7. 
9. Cavaghan MK, Ehrmann DA, Polonsky KS. Interactions between insulin resistance and insulin secretion in the development of glucose intolerance. J Clin Invest. 2000;106(3):329-333.

10. González-Posada JM, Hernández D, Bayés GB, Garcia Perez J, Rivero Sanchez M. Impact of diabetes mellitus on kidney transplant recipients in Spain. Nephrol Dial Transplant. 2004;19(Suppl 3): iii57-iii61.

11. Kasiske BL, Snyder JJ, Gilbertson D, Matas AJ. Diabetes mellitus after kidney transplantation in the United States. Am JTransplant. 2003;3(2): 178-185.

12. Revanur VK, Jardine AG, Kingsmore DB, Jacques BC, Hamilton DH, Jindal RM. Influence of diabetes mellitus on patient and graft survival in recipients of kidney transplantation. Clin Transplant. 2001;15(2): 89-94.

13. Hjelmesaeth J, Hartmann A, Leivestad T, et al. The impact of earlydiagnosed new-onset post-transplantation diabetes mellitus on survival and major cardiac events. Kidney Int. 2006;69(3):588-595.

14. Cosio FG, Kudva Y, van der Velde M, et al. New onset hyperglycemia and diabetes are associated with increased cardiovascular risk after kidney transplantation. Kidney Int. 2005;67(6):2415-2421.

15. Hjelmesaeth J, Sagedal S, Hartmann A, et al. Asymptomatic cytomegalovirus infection is associated with increased risk of new-onset diabetes mellitus and impaired insulin release after renal transplantation. Diabetologia. 2004;47(9):1550-1556.

16. Martínez-Castelao A, Hernández MD, Pascual J, et al. Detection and treatment of post kidney transplant hyperglycemia: a Spanish multicenter cross-sectional study. Transplant Proc. 2005;37(9):3813-3816.

17. Roland M, Gatault P, Al-Najjar A, et al. Early pulse pressure and low-grade proteinuria as independent long-term risk factors for newonset diabetes mellitus after kidney transplantation. Am J Transplant. 2008;8(8):1719-1728.

18. Joss N, Staatz CE, Thomson AH, Jardine AG. Predictors of new onset diabetes after renal transplantation. Clin Transplant. 2007;21(1): 136-143.

19. Baltar J, Ortega T, Ortega F, et al. Posttransplantation diabetes mellitus: prevalence and risk factors. Transplant Proc. 2005;37(9):3817-3818.

20. Bayés B, Granada ML, Pastor MC, et al. Obesity, adiponectin and inflammation as predictors of new-onset diabetes mellitus after kidney transplantation. Am J Transplant. 2007;7(2):416-422.
21. Porrini E, Delgado P, Alvarez A, et al. The combined effect of pre-transplant triglyceride levels and the type of calcineurin inhibitor in predicting the risk of new onset diabetes after renal transplantation. Nephrol Dial Transplant. 2008;23(4):1436-1441.

22. Rodrigo E, Santos L, Pinera C, et al. Early prediction of new-onset diabetes mellitus by fifth-day fasting plasma glucose, pulse pressure, and proteinuria. Transplant Proc. 2011;43(6):2208-2210.

23. Israni AK, Snyder JJ, Skeans MA, Kasiske BL. Clinical diagnosis of metabolic syndrome: predicting new-onset diabetes, coronary heart disease, and allograft failure late after kidney transplant. Transpl Int. 2012;25(7):748-757.

24. Luan FL, Langewisch E, Ojo A. Metabolic syndrome and new onset diabetes after transplantation in kidney transplant recipients. Clin Transplant. 2010;24(6):778-783.

25. Bayer ND, Cochetti PT, Anil Kumar MS, et al. Association of metabolic syndrome with development of new-onset diabetes after transplantation. Transplantation. 2010;90(8):861-866.

26. American Diabetes Association. Diagnosis and classification of diabetes mellitus. Diabetes Care. 2007;30(Suppl 1):S42-S47.

27. Al Saran K, Elsayed S, Sabry A, Hamada M. Obesity and metabolic syndrome in hemodialysis patients: single center experience. Saudi J Kidney Dis Transpl. 2011;22(6):1193-1198.

28. Stolic R, Trajkovic G, Peric V, et al. Ucestalost i karakteristike metabolickih poremecaja kodbolesnika lecenih hronicnim hemodijalizama. [Frequency and characteristics of metabolic disorders in patients on haemodialysis]. Vojnosanit Pregl. 2008;65(3):205-209. Serbian.

29. Jalalzadeh M, Mohammadi R, Mirzamohammadi F, Ghadiani MH. Prevalence of metabolic syndrome in a hemodialysis population. Iran J Kidney Dis. 2011;5(4):248-254.

30. Wu CC, Liou HH, Su PF, et al. Abdominal obesity is the most significant metabolic syndrome component predictive of cardiovascular events in chronic hemodialysis patients. Nephrol Dial Transplant. 2011;26(11): 3689-3695.

31. Tu SF, Chou YC, Sun CA, Hsueh SC, Yang T. The prevalence of metabolic syndrome and factors associated with quality of dialysis among hemodialysis patients in Southern Taiwan. Glob J Health Sci. 2012;4(5):53-62.

\section{Publish your work in this journal}

Diabetes, Metabolic Syndrome and Obesity: Targets and Therapy is an international, peer-reviewed open-access journal committed to the rapid publication of the latest laboratory and clinical findings in the fields of diabetes, metabolic syndrome and obesity research. Original research, review, case reports, hypothesis formation, expert opinion and commentaries are all considered for publication. The manuscript management system is completely online and includes a very quick and fair peer-review system, which is all easy to use. Visit http://www.dovepress.com/testimonials.php to read real quotes from published authors. 